\title{
A Hybrid MPPT Technique for Solar Photovoltaic System under Partial Shading ${ }^{\dagger}$
}

\author{
Hafiz Muhammad Tayyab ${ }^{1}\left[\right.$, Yaqoob Javed ${ }^{2}$, Irfan Ullah ${ }^{3, *}$, Abid Ali Dogar ${ }^{1}$ and Burhan Ahmed ${ }^{1}$ \\ 1 Department of Electrical Engineering, Minhaj University Lahore, Lahore 54770, Pakistan; \\ tayyabraees@gmail.com (H.M.T.); abidali.ee@mul.edu.pk (A.A.D.); burhanahmed777@gmail.com (B.A.) \\ 2 Department of Electrical Engineering, COMSATS University, Lahore 54000, Pakistan; \\ yaqoobsheikh@gmail.com \\ 3 Department of Electrical Engineering, University of Management and Technology, Lahore 54770, Pakistan \\ * Correspondence: irfanullah@umt.edu.pk; Tel.: +92-300-9572152 \\ + Presented at the 1st International Conference on Energy, Power and Environment, Gujrat, Pakistan, \\ 11-12 November 2021
}

Citation: Tayyab, H.M.; Javed, Y.; Ullah, I.; Dogar, A.A.; Ahmed, B. A Hybrid MPPT Technique for Solar Photovoltaic System under Partial Shading. Eng. Proc. 2021, 12, 28. https://doi.org/10.3390/ engproc2021012028

Academic Editor: Shahid Iqbal

Published: 23 December 2021

Publisher's Note: MDPI stays neutral with regard to jurisdictional claims in published maps and institutional affiliations.

Copyright: (C) 2021 by the authors. Licensee MDPI, Basel, Switzerland. This article is an open access article distributed under the terms and conditions of the Creative Commons Attribution (CC BY) license (https:// creativecommons.org/licenses/by/ $4.0 /)$.
Abstract: A major problem in the photovoltaic (PV) system is to determine the maximum power point (MPP) and to overcome the limitations of environmental change. To resolve the limitation of different techniques with high convergence rate and less fluctuations, a hybrid model of fractional open circuit voltage is proposed. For partial shading, incremental conductance is used. The proposed technique is extremely useful, provides high efficiency, and takes less time to achieve the MPP. The tenacity of the proposed method has been checked using MATLAB/Simulink, which clearly shows that the proposed technique has high efficiency compared to other MPP tracking methods.

Keywords: hybrid model; FOCV; improve IC

\section{Introduction}

To cater to the high demand for energy as per variance in load, it is important to consider changing ecological circumstances, as well as partial shading. In the past, a variety of projects and an abundance of research has worked towards a plan to determine maximum power point tracking [1]. These various techniques urge the PV system to work around global maxima (GM) by harmonizing the speed impedance with load impedance [2]. They can be divided into direct method and indirect method. Techniques such as: the Perturb and Observe method (P\&O); incremental conductance (IC); FLBC (Fuzzy Logics-based Control); ANN (Artificial Neural Network); PSO(Particle Swarm Optimization); GA (Genetic Algorithm); DE (Differential Evaluation); ACM (Ant Colony Method); BFO(Bacterial Foraging Optimization); ABC (Artificial Bee Colony); GPS (Generalized Pattern Search); and GFO (Grey Wolf Optimization) can be used as indirect methods, and Fractional Open Circuit Voltage (FOCV) and Fractional Short Circuit Current (FSCC) can be used as direct methods to reach MPP [3].

\section{A. PV Models}

When PV is connected to some measurement equipment source, PV characteristics will be obtained. These PV modules are either connected in parallel or series position to construct PV string or array, as shown in Figure 1. 


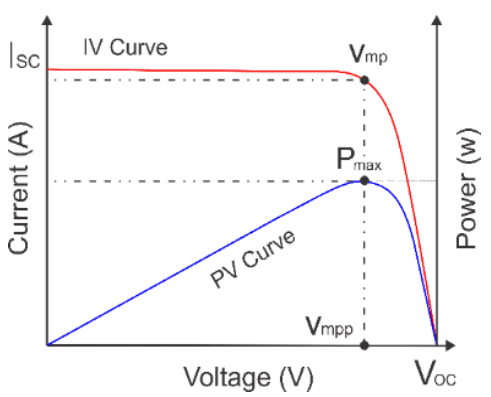

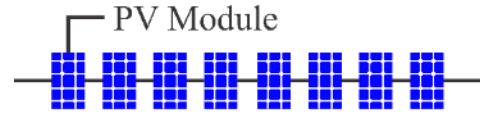

PV String

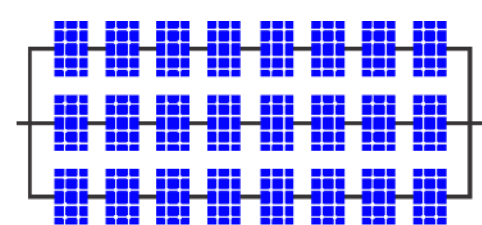

PV Array

Figure 1. PV Characteristic Curve and Array.

The main limitations of the PV system are its lack of functional effects in the dark or under shaded conditions; it also has a high installation cost, whereas energy conversion efficiency is quite low [4]. Additionally, it gives non-linear IV (Current-Voltage) and PV (Power-Voltage) characteristics curves through abrupt changes in environmental conditions and partial shading. Taking these issues into consideration it is of great importance to operate the PV array at MPP.

B. Incremental Conductance

IC is one of the fastest and most competent methods of conventional algorithms. This conductance works on the principal slope of the PV curve. The maximum value of the power slope is zero and the slope is negative when MPP is on the left side, while it is positive when MPP is on the right side [5].

\section{Fractional Open Circuit Voltage}

To find $\mathrm{V}_{\mathrm{PP}}$ and $\mathrm{V}_{\mathrm{MPP}}$, it is important to remove the load to calculate the $\mathrm{V}_{\mathrm{OC}}$ by shutting down the converter. However, this is a difficult task. There is also another problem concerning $\mathrm{MPP}$ - whenever the value of irradiance changes, it needs to be found out again and again [6]. It is also not possible to calculate real $M_{P P}$ due to the estimation. selecting pilot cells- $\mathrm{V}_{\mathrm{OC}}$ can be determined, but the cost of the system will also elevate. $\mathrm{V}_{\mathrm{MPP}}$ can be easily estimated if the $\mathrm{V}_{\mathrm{OC}}$ is measured [7], as shown in Figures 2 and 3.

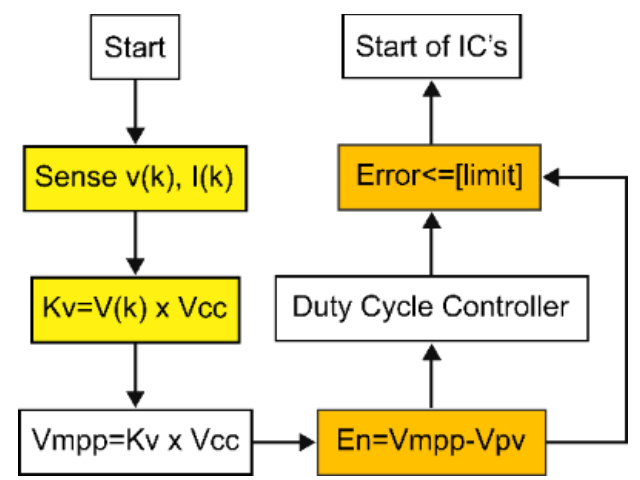

Figure 2. Block diagram of FOCV. 


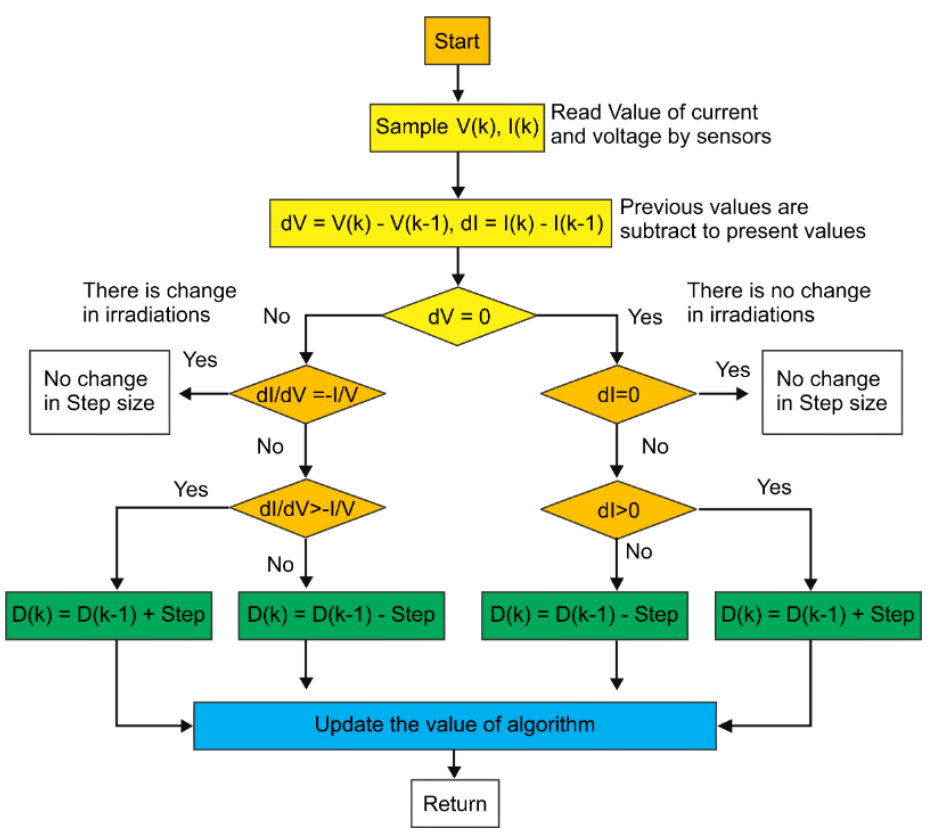

Figure 3. Block diagram of IC.

\section{Proposed Technique}

In this research, a combination of two methods, both conventional and non-conventional, for achieving global maximum point (GMP) have been used. The whole process of this research is divided into two stages.

Stage 1: Implementation of Fractional Open circuit Voltage.

Stage 2: Implementation of Incremental Conductance.

Fractional open circuit voltage divides the whole power voltage $(\mathrm{P}-\mathrm{V})$ curve into many sections and then estimates the section in which the global maximum point (GM) is possible to achieve. Following this, incremental conductance is used to determine the exact peak. The PV Module parameter used is Kyocera KC200GT as shown in Table 1.

Table 1. Kyocera KC200GT Parameters.

\begin{tabular}{ccc}
\hline Parameters & Unit & Electrical Data \\
\hline Nominal Power Pmax & $\mathrm{W}$ & 200 \\
\hline Maximum Voltage $\mathrm{V}_{\mathrm{MPP}}$ & $\mathrm{V}$ & 26.8 \\
\hline Maximum Current $\mathrm{I}_{\mathrm{MPP}}$ & $\mathrm{A}$ & 7.61 \\
\hline Open Circuit Voltage $\mathrm{V}_{\mathrm{OC}}$ & $\mathrm{V}$ & 32.9 \\
\hline Open Circuit Current Isc & $\mathrm{A}$ & 8.24 \\
\hline Output Efficiency & $\%$ & 13.5 \\
\hline Maximum Voltage of System & VDC & 1000 \\
\hline Temperature factor of PN & $\% / C 0$ & -0.0044 \\
\hline Temperature factor of VDC & $\mathrm{V} / \mathrm{C} 0$ & -0.0032 \\
\hline Temperature factor of Isc & mA/C0 & 0.0004 \\
\hline TNOCT & $\mathrm{C} 0$ & 47 \\
\hline Number of Cell & - & 54 \\
\hline
\end{tabular}

According to the principle of stage 1 algorithm, the maximum power point remains a constant fraction of the open circuit voltage. In photovoltaic arrangement, the open circuit voltage of cells is used and determined as the input to the controller. 
According to different studies, there is an association among the MPP voltage and the Open Circuit Voltage $\left(\mathrm{V}_{\mathrm{OC}}\right)$ in the other methods of Fractional Open Circuit, which varies with temperature and illumination.

\section{Result and Discussion}

Concerning different shading conditions, multiple peaks emerge, and at different peaks there are different power levels. By using this formula, a different value of voltage at a different peak can easily be computed:

$$
\frac{V_{0}}{n} \times s \times F F
$$

By using this formula, the Fill Factor can be easily computed

$$
F F=\frac{I_{S(M P P)} \times V_{0(M P P)}}{I_{S C} \times V_{O C}}
$$

$V_{0(M P P)}$ and $I_{S(M P P)}$, the Open circuit voltage and short circuit current of module at maximum power point, while $I_{S C}, V_{O C}$ are the short circuit current and open circuit voltage of the module as shown in Table 2.

Table 2. Voc values with different peaks.

\begin{tabular}{ccc}
\hline No of Panels & No of Peaks & Open Circuit Voltage \\
\hline 2 & 2 & 65.8 \\
4 & 5 & 131.6 \\
6 & 6 & 197.4 \\
8 & 8 & 263.2 \\
10 & 10 & 329 \\
\hline
\end{tabular}

Fill Factor is a constant and its value is equal to 0.8 .

When ten modules are connected in a series, they absorb equally and present full radiation, producing a healthy IV Curve, as displayed in Figure 4. If a fault arises due to shade, the IV curve displayed in Figure 4 provides ten peaks due to the bypass diode, compared to the healthy curve. The power-voltage curve provides ten peaks compared to the healthy condition. At 1000 irradiance, the power curve presented in Figure 5 is maximum effective and produces one peak, but in case of shading it gives ten peaks due to the bypass diode.

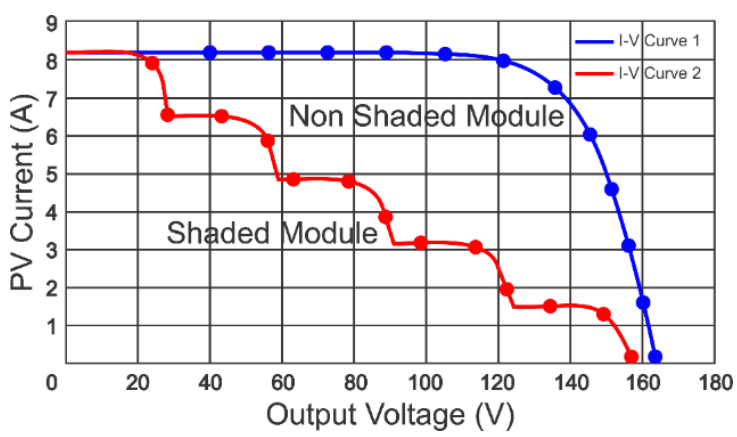

Figure 4. IV Curve healthy and shaded condition. 


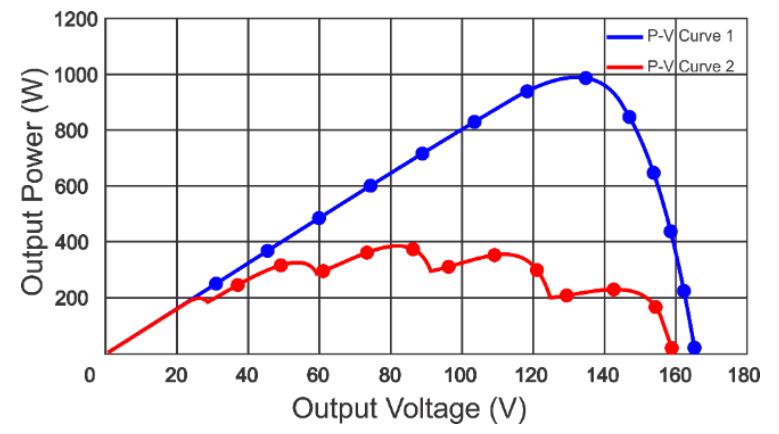

Figure 5. PV Curve healthy and shaded condition.

Table 3 shows that when modules are under different shading conditions, regardless of the order, their peaks are at same voltage level.

Table 3. Open circuit voltage in series.

\begin{tabular}{|c|c|c|c|c|c|c|c|c|c|c|}
\hline $\begin{array}{c}\text { No of } \\
\text { Modules }\end{array}$ & 1st Peak & 2nd Peak & 3rd Peak & 4th Peak & 5th Peak & 6th Peak & 7th Peak & 8th Peak & 9th Peak & 10th Peak \\
\hline 1 & 26.3 & & & & & & & & & \\
\hline 2 & 26.3 & 52.64 & & & & & & & & \\
\hline 3 & 26.3 & 52.64 & 78.96 & & & & & & & \\
\hline 4 & 26.3 & 52.64 & 78.96 & 105.28 & & & & & & \\
\hline 5 & 26.3 & 52.64 & 78.96 & 105.28 & 131.6 & & & & & \\
\hline 6 & 26.3 & 52.64 & 78.96 & 105.28 & 131.6 & 157.92 & & & & \\
\hline 7 & 26.3 & 52.64 & 78.96 & 105.28 & 131.6 & 157.92 & 184.24 & & & \\
\hline 8 & 26.3 & 52.64 & 78.96 & 105.28 & 131.6 & 157.92 & 184.24 & 210.56 & & \\
\hline 9 & 26.3 & 52.64 & 78.96 & 105.28 & 131.6 & 157.92 & 184.24 & 210.56 & 236.88 & \\
\hline 10 & 26.3 & 52.64 & 78.96 & 105.28 & 131.6 & 157.92 & 184.24 & 210.56 & 236.88 & 263.2 \\
\hline
\end{tabular}

\section{Conclusions}

In this study, a new technique of hybrid MPPT is proposed based on INC and FOCV and completed under Standard Test Conditions (STC). In an unchanging environmental condition, it is proved that FOCV and INC produces low oscillation power loss at peak compared to other techniques, while in shaded conditions, the proposed scheme somehow acts the same as MPP. Firstly, improved INC decreased the step time and improved the convergence speed in a different changing environment. This technique is easy to implement on hardware and software, but it is less resourceful in a quickly fluctuating environment, especially in partially shaded conditions. The advantage of this method is that it is easy to implement, it has the efficiency of a solar panel, it reduces the cost of a photovoltaic system, it has a low maintenance cost, and it is a natural source that can be utilized as energy.

Institutional Review Board Statement: Not Applicable.

Informed Consent Statement: Not Applicable.

Data Availability Statement: Not Applicable.

\section{References}

1. Ahmad, R.; Murtaza, A.F.; Sher, H.A.; Shami, U.T. An analytical approach to study partial shading effects on PV array supported by literature. Renew. Sustain. Energy Rev. 2017, 74, 721-732. [CrossRef]

2. Dinniyah, F.S.; Wahab, W.; Alif, M. Simulation of Buck-Boost Converter for Solar Panels using PID Controller. Energy Procedia 2017, 115, 102-113. [CrossRef]

3. Mohammad, S.S.; Devaraj, D. Simulation of Incremental Conductance MPPT based two phase interleaved boost converter using MATLAB/Simulink. In Proceedings of the 2015 IEEE International Conference on Electrical, Computer and Communication Technologies ICECCT, Coimbatore, India, 5-7 March 2015; pp. 1-6. [CrossRef] 
4. Ahmed, J.; Salam, Z. An Accurate Method for MPPT to Detect the Partial Shading Occurrence in a PV System. IEEE Trans. Ind. Inform. 2011, 13, 2151-2161. [CrossRef]

5. Muni, T.V.; Lalitha, S.V.N.L.; Suma, B.K.; Venkateswaramma, B. A new approach to achieve a fast-acting MPPT technique for solar photovoltaic system under fast varying solar radiation. Int. J. Eng. Technol. 2018, 7, 131-135. [CrossRef]

6. Sivakumar, P.; Kader, A.A.; Kaliavaradhan, Y.; Arutchelvi, M. Analysis and enhancement of PV efficiency with incremental conductance MPPT technique under non-linear loading conditions. Renew. Energy 2015, 81, 543-550. [CrossRef]

7. Kamran, M.; Mudassar, M.; Fazal, M.R.; Asghar, M.U.; Bilal, M.; Asghar, R. Implementation of improved Perturb \& Observe MPPT technique with confined search space for standalone photovoltaic system. J. King Saud Univ.-Eng. Sci. 2020, 32, $432-441$. [CrossRef] 